\title{
A POLÍTICA LINGUÍSTICA NA REGIÃO FRONTEIRIÇA BRASIL-GUIANA FRANCESA: PANORAMA E CONTRADIÇÕES
}

\author{
LANGUAGE POLICY IN THE BORDER REGION OF \\ BRAZIL AND FRENCH GUIANA: PANORAMA AND \\ CONTRADICTIONS
}

\section{Karen Kênnia Couto Silva}

\section{RESUMO}

Os estudos sobre a política linguística no Brasil ainda são recentes. Destarte um grande interesse em investigar a problemática da política linguística em contextos de fronteira, a maioria dos estudos teve como objeto de pesquisa a situação linguística nas fronteiras hispanobrasileiras. Assim, o objetivo deste artigo é problematizar a política linguística atualmente implementada na fronteira do Brasil com a Guiana Francesa. Para tanto, procuramos, em um primeiro momento, traçar um panorama de política linguística evidenciando a evolução da área ao longo de cinco décadas. Em um segundo momento, buscamos entender o histórico da relação bilateral Brasil-Guiana Francesa como forma de melhor compreender a constituição da política linguística nesse território fronteiriço. Por fim, analisamos estudos e documentos oficiais que trazem dados relativos à situação sociolinguística e questões relativas à política linguística oficial adotada. Com base nos dados encontrados na literatura, observam-se fortes indícios de uma carência de ações por parte do poder público no sentido de favorecer o ensino do Francês na fronteira brasileira, não obstante o fato de que tal idioma é amplamente utilizado nas relações sociais e comerciais na área fronteiriça. Diferentemente do observado em outras áreas de fronteira do território nacional, a fronteira Brasil-Guiana Francesa carece de instrumentos de política linguística que dêem suporte à população local, como é caso do "Programa Escolas Interculturais de Fronteira (PEIF)", uma iniciativa multilateral que prevê educação bilíngue no âmbito do MERCOSUL. Essas constatações nos encorajam a assumir que é necessário compreender melhor as idiossincrasias da região fronteiriça BrasilGuiana Francesa para que as necessidades prementes da população local sejam consideradas na conformação de uma política linguística adequada à realidade da faixa fronteiriça entre o Brasil e a Guiana Francesa.

Palavras-chave: política linguística; Guiana Francesa; fronteira

\section{ABSTRACT}

Studies on language policy in Brazil are still recent. Although there is great interest in researching the issue of language policy in border contexts, the research focus of the majority

\footnotetext{
*Universidade Federal de Minas Gerais, Belo Horizonte, MG. Brasil. karenbhz@yahoo.com.br http://dx.doi.org/10.1590/010318138648556261591
} 
of studies has been the linguistic situation in Hispanic-Brazilian border regions. Thus, the objective of this article is to problematize the language policy currently implemented at the border of Brazil and French Guiana. In order to do so, we will first to give an overview of the language policy, evidencing the changes in the area over five decades. Second, we will attempt explore the history of the bilateral relationship between Brazil and French Guiana, as a way to better understand the constitution of language policies in this frontier territory. At the end, we will analyze studies and official documents that contain data regarding the sociolinguistic situation and issues related to the official, adopted language policy. Based on the data presented in the literature, there is strong evidence of a lack of action by public authorities to promote the teaching of French at the Brazilian border, despite the fact that the language is widely used in social and business relations in the border area. Unlike what is observed in other frontier areas of the national territory, the Brazil-French Guiana border lacks language policy tools to support the local population, such as the "Intercultural Border Schools Program (PEIF)", a multilateral initiative that provides bilingual education within the framework of MERCOSUL. In light of these findings, we can assume that there is a need for a better understanding of the idiosyncrasies of the Brazil-French Guiana border region, so that the pressing needs of the local population can be considered in the establishment of a language policy adapted to the reality of the border between Brazil and French Guiana. Keywords: language policy; French Guiana; boundary

\section{INTRODUÇÃO}

Muito se tem discutido sobre o protagonismo que a política linguística tem assumido no mundo globalizado. Questões como movimento migratório, ocupação militar, trocas comerciais e, mais recentemente, áreas fronteiriças têm sido alguns dos temas mais frequentes discutidos na sociedade. Atualmente, a pesquisa em Política Linguística tem cada vez mais se debruçado sobre temas que impõem novos desafios aos países e suas respectivas escolhas acerca da política linguística, que não desconsidera a participação dos sujeitos. Mesmo diante desse cenário, os estudos sobre a política linguística no Brasil ainda são recentes. Destarte um grande interesse em investigar a problemática da política linguística em contextos de fronteira, a maioria dos estudos teve como objeto de pesquisa a situação linguística nas fronteiras hispano-brasileira. A contribuição teórica desses estudos permitiu que o Brasil conformasse uma política linguística bilateral que também abarcasse a particularidade linguística complexa das regiões fronteiriças hispanófonas. Nesse quesito, o advento MERCOSUL foi fator preponderante para a formulação e implementação de uma política linguística bilateral, multilateral e que contou com a participação de diferentes atores e agências governamentais, bem como da sociedade em geral. 
Segundo Nascimento (2013), até a década de 90, poucos foram os estudos fundamentados sobre as fronteiras brasileiras, tais como os Hensey (1972) e Elizaincin et al. (1987), que propuseram pesquisas sobre a fronteira do Brasil/ Uruguai. A partir dos anos 2000, ainda de acordo com a autora, as pesquisas sobre fronteiras hispanófonas intensificaram-se e tais estudos ${ }^{1}$ procuraram abordar o contexto do contato linguístico em áreas de fronteira: Espiga (2006) sobre a fronteira Chui/Chuy, Lupski (2011) sobre a fronteira Brasil/Bolívia, Couto (2011) sobre a zona de fronteira Brasil/Uruguai, Braz (2010) e Silva (2012) sobre a fronteira Brasil/Venezuela, Barbosa (2009) sobre a fronteira Brasil/Colômbia e Ferreira \& Silva (2012) sobre a fronteira Brasil/Bolívia. De fato, a criação do MERCOSUL e os inúmeros acordos bilaterais firmados contribuíram muito para o aumento do interesse dos pesquisadores em debater as políticas linguísticas nas regiões hispanófonas. A nosso ver, a produção científica sobre política linguistica no âmbito das fronteiras do MERCOSUL deveria servir de estímulo para despertar também o interesse de pesquisa em outros contextos fronteiriços. Contudo, tal fato, infelizmente não tem sido observado. Atualmente, poucos são os estudos interessados em investigar as fronteiras norte do país, o que, consequentemente, torna essas regiões subapreciadas na literatura científica e carentes de políticas linguísticas que contemplem as particularidades e a complexidade linguísticas de seus respectivos contextos fronteiriços. Nesse sentido, instiga o pensamento constatar que o Brasil, com seus $730 \mathrm{~km}$ de fronteira com a Guiana Francesa, não possua também uma política linguística focalizada (efetiva) para atender as necessidades dessa região fronteiriça, tal qual já se observa na fronteira sul do país. Como os estudos acadêmicos voltados a essa região não são em grande número, a falta de problematização da política linguística na região fronteiriça do Brasil com a Guiana Francesa em pouco tem contribuído para a superação dos conflitos linguísticos e culturais enfrentados pela população fronteiriça.

Assim, no percurso que se pretende neste trabalho, busca-se em um primeiro momento apresentar o percurso epistemológico pelo qual a área de política linguística trilhou. Em um segundo momento, tem-se a intenção de apresentar um breve panorama histórico das relações Brasil-Guiana Francesa buscando uma retrospectiva desde a formação da fronteira até os dias atuais, ressaltando algumas ações bilaterais entre os respectivos países. Em um terceiro momento, pretende-se resenhar três estudos sociolinguísticos realizados sobre a fronteira Brasil-Guiana Francesa como forma de se tentar compreender a formação do território fronteiriço. Será igualmente importante a análise de estudos e documentos oficiais que trazem

1. As referências completas desses estudos estão em Nascimento (2013). 
dados relativos à situação sociolinguística e questões relativas à política linguística da região fronteiriça. As questões que direcionaram nossa investigação foram às seguintes: Como se configura o quadro sociolinguístico da fronteira Brasil-Guiana Francesa? $\mathrm{O}$ que os estudos sociolinguísticos revelam sobre a realidade linguística fronteiriça? Será que as políticas linguísticas oficiais adotadas pelo Brasil se alinham com às necessidades da população fronteiriça em questão?

\section{AS MÚLTIPLAS FACETAS DE POLÍTICA LINGUÍSTICA}

A área de Política Linguística pode ser compreendida de diferentes maneiras, dependendo do lugar teórico a partir do qual é definido e do momento histórico ao qual sua definição está atrelada. Adentrar nesse campo de estudo é percorrer uma história epistemológica de mais de cinco décadas, com diferentes aportes teóricos e metodológicos. Para basear nossa discussão, trazemos à baila um importante artigo de cunho teórico, produzido por Thomas Ricento (2000)², que nos brinda com uma rica reconstrução da história epistemológica da área, desde as primeiras pesquisas na década de 1960 até as publicações mais recentes. Apoiamo-nos, igualmente, nas perspectivas teóricas apresentadas por Spolsky (2004) e Shohamy (2006) por considerarmos as contribuições dos autores pertinentes para o presente trabalho.

Em linhas gerais, a história da disciplina política linguística ${ }^{3}$ apresenta três gerações de estudos. A primeira geração de autores nas décadas de 60 e 70 (FISHMAN, 1974; NEUSTUPNÝ, 1974; RUBBIN e JERNUDD, 1971; FERGUSON e DAS GUPTA, 1968 apud RICENTO, 2000), aglutinaram seus estudos a partir de pressupostos que visavam superar os "problemas" linguísticos enfrentados pelas nações à época: da heterogeneidade linguística, da modernização linguística e da cientificidade. Nas palavras do autor,

the three elements in the first phase in LPP [language policy and planning] work are (1) decolonization and state formation (macro sociopolitical), (2) the predominance of structuralism in social sciences (epistemological), and (3) the pervasive belief, at least in the West, that language problems could be solved through planning, especially within the public sector (strategic). (RICENTO, 2000, p. 10).

2. O artigo Historical and Theoretical perspectives in Language Policy and Planning foi publicado no livro Ideology, Politics and Language Policies, coordenado pelo mesmo autor.

3. Ricento usa "política linguística" como um termo subordinante que engloba "planejamento linguístico". Para o autor, a política e o planejamento linguísticos dizem respeito não apenas aos atos oficiais e não-oficiais, mas também aos processos históricos e culturais que influenciam as atitudes e práticas da sociedade sobre o uso da linguagem e status. 
Como é evidenciada na passagem acima, a resolução dos "problemas" linguísticos foi um dos principais objetivos da política linguística nessa primeira fase. A diversidade linguistica era vista como um "problema" na formação dos grandes Estados e o único modo de garantir a língua da "nação" seria através um planejamento linguístico sistematizado. Buscava-se assim seguir os propósitos da modernização tão requeridos durante o século XX. É nessa época que surge a ideia de planejamento linguístico ${ }^{4}$ como sendo uma atividade, marcadamente intervencionista implementada pelo ator estatal. Nesse particular, há uma distinção a ser considerada: planejamento de corpus e de status (Haugen, 1996). Como assevera Ricento (2000), a intervenção no corpus (forma) da língua foi uma estratégia utilizada com frequência pelos linguistas dessa primeira fase, pois se almejava o desenvolvimento dos sistemas de escritas, de gramáticas e de manuais de línguas. De igual forma, a intervenção no status da língua foi amplamente empregada, uma vez que o objetivo era ampliar o status das línguas européias (principalmente o francês e o inglês), nos domínios formais e restringir o status das línguas locais (indígenas) a outros usos. O linguista LouisJean Calvet (1996), apesar de não se declarar teórico da primeira fase, defende a inseparabilidade do par política linguística e planejamento linguístico. Nas palavras do autor, política linguística seria "a determinação das grandes escolhas referentes às relações entre as línguas e a sociedade" (CALVET, 1996, p. 3) em contraposição ao planejamento linguístico que corresponderia aos modos de implementação dessas decisões e escolhas, ou seja, de uma dada política. Devido à sua enorme contribuição teórica e metodológica, as ideias de Calvet têm influenciado até hoje os estudos na área.

Nas décadas de 70 e 80 tem-se uma continuação dos temas discutidos no período anterior. Questões como "modernização" e "desenvolvimento nacional" continuam a imperar entre os pesquisadores, todavia outros assuntos, tais como, o papel da "língua" e da "cultura" entram para as agendas científicas. Essas décadas marcam igualmente um período de críticas (KAPLAN e BALDAUF, 1997; SCHIFFMAN, 1996; TOLLEFSON, 1991; COBARRUBIAS, 1983 apud RICENTO, 2000) às abordagens anteriores, acusando-as de se autoproclamarem ideologicamente neutras. De acordo com Ricento (2000), os efeitos políticos, sociais e econômicos do contato entre as línguas e as implicações sociais dos aspectos não-explícitos dos processos de política linguística foram as principais preocupações dos teóricos da segunda fase. Contudo, nem mesmo a revisão da teoria e o reemprego de alguns termos foram capazes de modificar a visão que vigorava na época. Veja a seguir:

4. O termo foi introduzido por Einar Haugen em 1966. 
Historical inequalities and conflicts did not diminish with the selection of an indigenous language for Low variety functions, and designation of European languages for High functions tended to perpetuate socioeconomic asymmetries based on education, access to which was socially controlled by dominant groups (internally), and influenced by regional and global economic interests (externally). (RICENTO, 2000, p. 16).

A análise cuidadosa do excerto acima nos indica que a política linguística, na segunda fase, representava um mecanismo de preservação dos interesses dos grupos hegemônicos e que o controle social ainda era o grande objetivo da época. Ainda nessa fase vigorava na política linguística a visão rígida de planejamento linguístico implementado por uma autoridade oficial ou, ao menos, a serviço desta.

Desde meados da década 80, surgem tentativas de superar, em alguma medida, o pressuposto de que a responsabilidade sobre a política linguística fosse sempre incumbência privativa do agente governamental. Nesse sentido, os grandes expoentes da dessa terceira geração (SCHIFFMAN, 1994; SPOLKSY, 2004; SHOHAMY, 2006) relativizaram o peso dos atores estatais nas formulações de políticas linguísticas, lançando um olhar crítico sobre as abordagens precedentes, mormente "estadocêntricas". A propósito da terceira fase, Spolsky assinala:

The first sociolinguists who tackled questions concerning language policy and planning were troubled by these questions, but were more concerned with solving the language problems of developing nations. [...]A second wave of scholars in the field became more concerned with developing models of linguistic human right on the basis of which they could encourage international groups to adopt specific policies. What is missing, however, was a systematic attempt to gather usable data on language policies at all levels. (SPOLSKY, 2004, 4-5) [grifo nosso]

Como se vê, de forma sucinta - mas nem por isso menos esclarecedora - o emérito linguista evidencia o avanço da disciplina que, em cinco décadas, deixou de ser vista simplesmente como um conjunto de intervenções planejadas e implementadas pelo agente oficial e passou a ser percebida como uma atividade que, nem sempre é explícita, e que, frequentemente, está vinculada às práticas linguísticas e atitudes dos falantes. Contudo, deve-se recordar que foi Schiffman (1996) o primeiro a propor a distinção entre política linguistica implícita - regras linguísticas (não-oficiais) manifestadas nas práticas sociais - em contraposição a política linguistica explíita - regras linguísticas veiculadas nas legislações oficias. Na concepção de Schiffman (1996), as representações de uma comunidade linguística relativamente à sua língua definem suas atitudes em relação a outras línguas. Coube a Spolsky (2004) defender a ideia de que as políticas linguísticas oficiais implementadas pelas agências governamentais nem sempre se coadunam com as políticas linguísticas de "fato" existentes na sociedade. Spolsky declarou igualmente que uma política 
linguística pode existir sem que um legislador a promova de forma explícita. Veja a seguir:

But language policy exists even where it has not been made explicit or established by authority. Many countries and institutions and social groups do not have formal or written language policies, so that the nature of their language policy must be derived from a study of their language practice or beliefs. Even where there is a formal, written language policy, its effect on language practices is neither guaranteed nor consistent. (SPOLSKY, 2004, p. 8).

Shohamy (2006), na mesma direção de Spolsky (2004), propõe ampliar o escopo da política linguística, levando em consideração, acima de tudo, as ações de política linguística formuladas por agentes da sociedade civil. Tal visão está diretamente associada com uma noção de língua como um sistema aberto, flexível, dinâmico, que varia de um falante para outro, em constante evolução. A pesquisadora busca desenvolver uma abordagem capaz de explicar o funcionamento da política linguística oculta (bidden language policy) ou de fato (de facto policy) que estão presentes nas sociedades atuais. Central nessa teoria é o conceito de "mecanismo" de política linguística, o qual, inclusive, nos importa reter. Para Shohamy, os mecanismos

represent overt and covert devices that are used as the means for affecting, creating, and perpetuating de facto language policies. They expand LPs [language policies] beyond official documents and towards an understanding of LPs in terms of the means used to influence policies. (SHOHAMY, 2006, p.54).

Dito de outro modo, os mecanismos são os meios pelos quais a política linguística é difundida no meio social. Uma vez integrados às agendas implícitas da política linguística, passam a atuar de forma implícita e/ou explícita em favor da sua concretização. As leis e decretos seriam exemplos de mecanismos explícitos ao passo que placas de rua e manuais de línguas seriam exemplos de mecanismos implícitos. A nosso ver, o ineditismo da proposta de Shohamy estaria em empregar mecanismos que influenciam, criam e reproduzem práticas linguísticas e, por conseguinte, formulam as reais políticas linguísticas.

A essa altura, já tendo delineado os principais relevos teóricos e metodológicos do breve percurso epistemológico da área, podemos assumir que a perspectiva de Shohamy é a que nos parece mais adequada para analisar a política linguística praticada em um contexto de fronteira. Embora não seja proposta do presente trabalho debater sobre o conceito fronteira, devemos destacar que a adoção do termo assume uma conotação especial em nosso propósito. Admitimos a premissa de que uma fronteira não é somente um lugar que marca o limite (físico) entre os territórios, mas, sobretudo, é "um espaço [social] em que se tocam culturas, etnias, línguas, nações" (STURZA, 2006, p. 26). Compreender a fronteira como 
um espaço social, significa pensar sobre o modo como as línguas se relacionam, integram-se e funcionam em um determinado espaço.

Desse modo, ao trabalharmos com essa noção de contexto fronteiriço, acreditamos que seja possível articular a visão tradicional de política linguística decisões feitas sobre a língua e seus usos -, sem excluir abordagens mais progressistas, sobretudo acerca dos mecanismos para a perpetuação de práticas linguísticas ocultas ou implícitas de uma comunidade.

\section{HISTÓRICO DE RELAÇÕES ENTRE BRASIL-GUIANA FRANCESA}

Nesta seção pretendemos destacar alguns fatos singulares da relação bilateral Brasil-Guiana Francesa. Para tanto, nos apoiaremos em dados oriundos dos Ministérios das Relações Exteriores, retirados do portal oficial do Itamaraty e no relatório ${ }^{5}$ intitulado Guiana Francesa-Amapá: melhor estruturar os territórios para intensificar os intercâmbios. Situados ao Nordeste da América do Sul, a Guiana Francesa, Coletividade Territorial e o Estado do Amapá, Estado da federação do Brasil, constituem, com o Suriname, a República Cooperativa da Guiana e o Sul da Venezuela, o Platô das Guianas. Esses dois territórios compartilham uma fronteira comum de 655 quilômetros, dos quais 360 são constituídos pelo rio Oiapoque.

Apesar de os intercâmbios culturais e comerciais não serem recentes entre as duas margens, a relação do Brasil com a Guiana Francesa é marcada por um longo histórico de divergências em razão de desacordos territoriais. A história entre a Guiana Francesa e o Brasil teve início com a ocupação francesa na região da Guiana em 1615. Durante os séculos XVI a XIX, houve uma disputa entre Portugal/ França e, em seguida, França/Brasil que resultou na ocupação luso-brasileira na Guiana Francesa entre 1809-1817, marcando uma época de Contestado pela faixa territorial. Esses intensos conflitos pelo território não cessaram nem mesmo com a assinatura do Tratado de Utrecht, em 1713, que demarcava o rio Vincent-Pinson como a fronteira oficial entre os países.

Em 1822, após a independência do Brasil, os franceses passam a disputar as posses de terra da cartografia do norte do atual Estado do Amapá. A arbitragem sobre a fronteira foi solucionada em 1990, com a assinatura do Laudo Suíço que cedia o território da parte norte do Amapá ao Brasil. A criação do Território Federal do Amapá (TFA) é realizada somente em 1943. De forma semelhante, a Guiana

5. Realizado em parceria entre a Agência Francesa de Desenvolvimento (AFD), Instituto Nacional de Estatística e Estudos Econômicos (INSEE) e Instituto de Emissão dos Departamentos de Ultramar (IEDOM). 
Francesa passou de colônia a departamento ultramarino francês em 1946, gozando de igualdade jurídica com os demais departamentos franceses. Durante o século XX, a Guiana Francesa e o Brasil passaram por limitações econômicas, e tal fato corroborou para que ambos os países procurassem uma convergência de interesse pelo desenvolvimento regional e estabelecessem uma relação de amizade. Ainda no século XX tem-se a construção da base espacial francesa, que oportunizou - $e$ estimulou - a imigração legal de trabalhadores brasileiros para a Guiana Francesa.

As relações bilaterais entre Brasil e Guiana Francesa tomaram um novo rumo nos anos 90, quer seja do ponto de vista local, nacional e continental (representado pela União Européia e o MERCOSUL). Emblemático nesse sentido é a organização de Comissões Mistas Transfronteiriças periódicas que tinham o objetivo de traçar ações conjuntas que, anos mais tarde, culminariam na assinatura do Acordo-Quadro (1996). Esse acordo visava uma política efetiva de desenvolvimento fronteiriço que pudesse trazer benefícios aos atores locais.

No século XXI, as relações bilaterais intensificam-se com a Parceria estratégica assinada entre os presidentes Lula e Chirac nos domínios da educação, línguas, temas migratórios e transfronteiriços e com as intensas visitas presidenciais nos respectivos países. No ano de 2005, o Acordo Relativo à Construção de uma Ponte Rodoviária sobre o Rio Oiapoque ligando a Guiana Francesa e o Estado do Amapá é assinado. Recentemente, em março de 2017, a ponte binacional foi inaugurada com a presença de oficiais do governo do Amapá e da Guiana Francesa. A ponte Oiapoque faz parte de um dos projetos estruturantes entre o Brasil e a Guiana Francesa e pode contribuir para aumento das perspectivas de abertura e intercâmbios entre os dois territórios. O quadro abaixo resume de forma sintética os principais acontecimentos que marcaram a relação bilateral Brasil-Guiana Francesa:

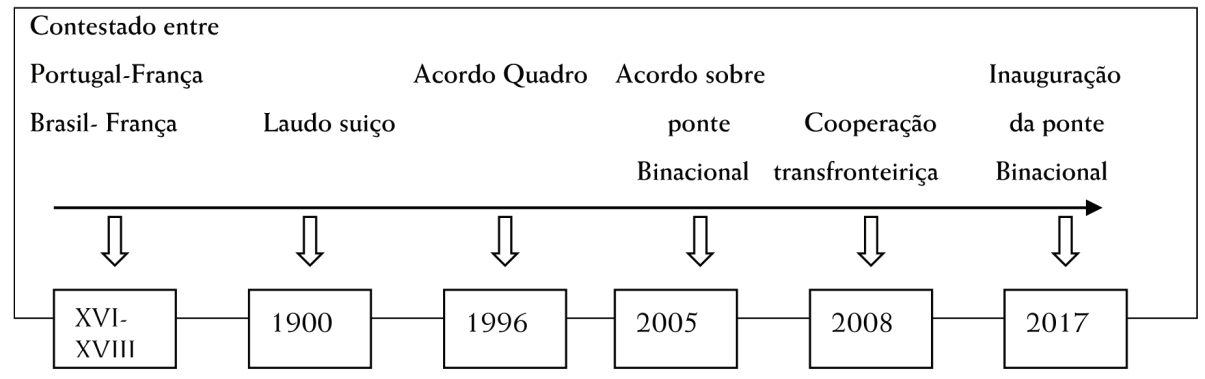

Figura 1. Fatos importantes entre Brasil-Guiana Francesa 
Conforme pode ser observado, o contexto fronteiriço é, por natureza de sua própria constituição, um contexto formado a partir de disputas, de conflitos de ciclos de aproximação e reaproximação. Para além das demarcações políticogeográficas, existe também uma demarcação um pouco mais sutil, mas não menos perceptível, que é justamente a demarcação da língua. Partindo do principio que a soberania nacional pressupõe unidade, esta se reflete de modo muito especial na língua. Nesse sentido, fazer parte da nação é estar sobre um mesmo território, falar uma mesma língua e estar submetido a um mesmo governo. Dessa forma, querer entender o contexto fronteiriço em sua dimensão histórica é importante para que possamos refletir sobre as dificuldades atuais de estabelecer uma política linguística bilíngue sob uma perspectiva institucional.

\section{ESTUDOS SOCIOLINGUÍSTICOS SOBRE A FRONTEIRA BRASIL-GUIANA FRANCESA}

Uma vez exposto o histórico das relações Brasil-Guiana Francesa, cumpre-nos agora apresentar três pesquisas sociolinguísticas assaz elucidativas sobre a fronteira Brasil-Guiana Francesa: a dissertação de Kelly Cristina Day Nascimento intitulada "A Situação Socio-Linguística da Fronteira Franco-Brasileira: Oiapoque \& Saint Georges", a dissertação de Marilucia Marques do Espírito Santo "De Oiapoque a SaintGeorges: uma pesquisa sociolinguística em meio escolar na fronteira Brasil e Guiana Francesa" e o artigo de Telma Pereira intitulado "Representação e aprendizagem de uma língua estrangeira: status da língua francesa em contexto urbano e de fronteira". Consideramos que tais estudos são representativos de uma amostra que tenciona explicitar a mesma realidade sociolinguística e nos fornecem um panorama geral sobre a situação linguística da região fronteiriça Brasil-Guiana Francesa.

\section{Estudo sociolinguístico de Kelly Cristina Day Nascimento}

O estudo pioneiro "A Situação Socio-Linguística da Fronteira FrancoBrasileira: Oiapoque \& Saint Georges" (NASCIMENTO, 2005) elabora um quadro sociolinguístico da fronteira franco-brasileira (identificando as línguas, os status e os domínios de uso) e busca discutir questões relativas às políticas linguísticas presentes ou ausentes naquela região. No âmbito da pesquisa foram consideradas quatro línguas em presença: o português, o francês, o crioulo e o patuá. Em termos metodológicos, a pesquisadora adotou vários instrumentos de coleta de dados, tais 
como, observação in loco, questionários (baseados na grade de análise de situações linguísticas propostas por Chaudenson) e entrevistas.

Em seu estudo, Nascimento (2005) afirma que as línguas fazem parte da "política de fronteira" e, como tal, são motivos de encontros e desencontros, aproximações e distanciamentos, inclusão e exclusão. A pesquisadora revela que a fronteira Brasil-Guiana Francesa é ainda pouco conhecida e que as especificidades dessa área não são levadas em conta. Nas palavras de Nascimento,

faz-se necessário portanto despertar a consciência de que não somos o país monolingue que muitos imaginam, que os contatos de fronteira não são exclusivamente com hispano-falantes e sobretudo que um país multilíngue e multicultural é antes de tudo "múltiplo" de realidades que demandam ações condizentes com os seus contextos sociais, políticos, econômicos e linguísticos diferenciados. (NASCIMENTO, 2005, p. 92).

A autora ressalta ainda, a falta de uma política linguística adequada à fronteira Brasil-Guiana Francesa, haja vista o favorecimento do ensino do inglês em detrimento do francês numa região francófona. Na visão da pesquisadora, o ensino do inglês torna-se pouco significativo, já que as pessoas que moram na fronteira não necessitam do idioma nas relações cotidianas e raramente viajam para países anglófonos. De maneira contrária, o ensino do francês se justificaria na medida em que os dados coletados no âmbito da pesquisa demonstraram que "a língua [francesa] é a segunda língua da região, está fortemente inserida no meio social e no trabalho, que existe uma demanda clara pelo ensino formal da língua na comunidade brasileira" (NASCIMENTO, 2005, p.93).

Interessante notar que, quase uma década depois, Nascimento (2013) atualiza e corrobora os resultados de sua dissertação de mestrado ${ }^{6}$. Embora tal artigo não seja objeto de análise no presente estudo, algumas considerações da autora contribuem para nossa discussão. No artigo, a autora busca discutir alguns reflexos sociais e linguísticos na fronteira ocasionados pelo contato linguístico. Nascimento (2013) constata novamente "o favorecimento do ensino da língua inglesa e espanhola em detrimento da língua francesa - refletindo a realidade nacional e não local" e que tal fato "impõe à comunidade brasileira mais uma situação de desvantagem frente à realidade vizinha" (NASCIMENTO, 2013, p. 181). A autora, contudo, diagnostica que a política linguística de caráter monolíngue não está restrita ao governo brasileiro, pois "a prática do monolinguismo instituída no Brasil e na França, baseada no princípio da nacionalidade, desconsidera o fator fronteiriço, sobretudo no que diz respeito ao ensino de línguas estrangeiras e /ou segundas

6. "Fronteiras linguísticas e fronteiras políticas: relações linguísticas e sociohistóricas na fronteira do Brasil com a Guiana Francesa", 2013. 
línguas" (NASCIMENTO, 2013, p.179). O teor dessas considerações permite-nos afirmar que o ensino do francês continua a ser preterido em relação ao ensino do inglês e do espanhol. Deve-se mais uma vez sublinhar que Nascimento reafirma as considerações feitas no âmbito da sua dissertação em 2005, quase uma década depois de seu estudo pioneiro. Embora não tenha sido um estudo de caráter longitudinal, as contribuições de Nascimento (2005 e 2013) nos encorajam a afirmar que não houve mudanças significativas em relação à política linguística implementada na região, deixando claro que a situação da política linguística continua dissonante no contexto fronteiriço.

\section{Estudo sociolinguístico de Marilucia Marques do Espírito Santo}

O estudo de Espírito-Santo (2009), uma dissertação de mestrado intitulada "De Oiapoque a Saint-Georges: uma pesquisa sociolinguística em meio escolar na fronteira Brasil e Guiana Francesa" revela também a ausência de uma ação políticolinguística relacionada à fronteira Brasil-Guiana Francesa, motivo o qual levou a pesquisadora a estudar a região. Estudar a situação linguística em uma escola do município de Oiapoque, no Amapá, foi a forma encontrada para discutir a formulação e implementação de uma política linguística que leve em consideração o contexto de fronteira.

Em suas considerações, Espírito-Santo (2009) ressalta que a fronteira, mais que um limite físico entre territórios, é um espaço onde as línguas entram em contato, as culturas se misturam e os povos se relacionam. No que diz respeito à fronteira Brasil-Guiana Francesa, a pesquisadora assevera que, essa fronteira necessita de "políticas públicas urgentes além das políticas educacionais". (ESPIRITO-SANTO, 2009, p. 94) uma vez que essa região está localizada no extremo norte do Brasil, longe das grandes decisões políticas e econômicas do país, e que raramente entra para pauta das discussões do Estado brasileiro. A pesquisadora revela que quatro línguas (francês, português, crioulo francês e indígenas) coexistem na região fronteiriça, exercendo papéis distintos e que a língua francesa tem potencial de crescimento na região já que aprender tal idioma significa ter ganhos sociais e econômicos.

Após a análise de dados coletados no município de Oiapoque e em uma escola municipal da fronteira Brasil-Guiana Francesa, a pesquisadora concluiu que a língua portuguesa é o idioma que predomina nos ambientes comunicativos, já que o português é a língua materna da maioria das pessoas entrevistadas (alunos e habitantes). Os dados sugerem um bilinguismo individual, uma vez que o francês, o patuá e o crioulo coexistem nos ambientes comunicativos analisados e que a escola é um ambiente bastante propício para o bilinguismo social, sendo a língua francesa 
a de maior representatividade. Os dados revelaram que os estudantes têm atitudes positivas em relação ao francês e isso é devido às condições "política, econômica e social a qual se encontra o vizinho" (ESPIRITO-SANTO, 2013, p. 95).

Ao comparar as fronteiras norte e sul, Espírito-Santo (2013) aponta que, as diferenças entre Oiapoque e Saint Georges - fronteira norte - são significativas no que diz respeito aos aspectos econômicos sociais e linguísticos (as línguas são diferentes e os países participam de blocos regionais distintos). Ainda, de acordo com a pesquisadora, as fronteiras sul possuem mais semelhanças do que diferenças (as línguas são semelhantes e os países participam do mesmo bloco regional - o MERCOSUL). Ademais, Espírito-Santo (2013) evidencia que a fronteira sul é favorecida por uma política linguistica, que é, inclusive, amparada pelo MERCOSUL - o Programa Escolas Interculturais de Fronteira, ao passo que a políticas linguística na fronteira norte "sem sido uma opção autônoma, sem a intervenção do Estado, mas feita pela comunidade escolar da Escola Estadual Joaquim Nabuco" (ESPIRITOSANTO, 2013, p. 95). A pesquisadora conclui, portanto, que não há acordos "políticos educacionais efetivos" (ESPIRITO-SANTO, 2013, p.96) na fronteira norte e assevera que a comunidade escolar necessita de políticas linguísticas efetivas em relação ao ensino da língua francesa. Nas palavras de Espírito-Santo:

\footnotetext{
A comunidade escolar ressente de uma política linguistica em relação ao ensino da língua francesa com propósito verdadeiramente comunicativo que considere as necessidades reais do dia a dia dos habitantes dessa região assim como dos alunos e que possibilite a mudança da realidade linguística, social e cultural (ESPIRITO-SANTO, 2013, p. 97).
}

\section{Estudo sociolinguístico de Telma Pereira}

No artigo "Representação e aprendizagem de uma língua estrangeira: status da língua francesa em contexto urbano e de fronteira" (PEREIRA, 2009), a pesquisadora apresenta algumas reflexões decorrentes de uma pesquisa sociolinguística sobre representação linguística meio universitário no Rio de Janeiro e na fronteira BrasilGuiana Francesa - cidades gêmeas Oiapoque-Saint George. O principal objetivo desse estudo é o de observar o papel reservado ao francês na área urbana e na zona fronteiriça. Uma vez que nosso presente trabalho propõe a análise de estudos na fronteira Brasil-Guiana Francesa, privilegiaremos o estudo realizado na fronteira e não discutiremos o trabalho realizado no âmbito universitário no Rio de Janeiro.

Em seu estudo sobre a fronteira Brasil-Guiana Francesa, Pereira propõe uma pesquisa de campo sobre representação linguística de 137 trabalhadores de Oiapoque de diferentes ramos e utiliza entrevistas semi-estruturadas e o questionário Chaudenson (2001) sobre a análise das situações linguísticas. Os 
formulários apontaram que o inglês é considerado uma língua útil na fronteira e isso se justifica pelo advento da Internet e pelo número crescente de turistas na região fronteiriça. $\mathrm{O}$ francês é usado frequentemente na área fronteiriça e que esse idioma é considerado, ao mesmo tempo, o mais fácil (por ser adquirido informalmente nas relações cotidianas) - e o segundo mais difícil (aquisição formal no ensino escolar). O estudo de Pereira (2009) revelou que o francês é a língua que a maioria das pessoas gostaria de aprender (57\%), em seguida do inglês (23\%).

$\mathrm{Na}$ conclusão, Pereira (2009) afirma que a representação favorável associada à possibilidade de uso faz com que o status de uma língua seja modificado. $\mathrm{O}$ frequente número de representações positivas da língua francesa veiculadas nos questionários: "língua mais bonita", "língua mais fácil", "língua que desejo aprender" leva a pesquisadora a afirmar que o francês é uma língua de crescimento em potencial em Oiapoque, o que certa forma converge com o estudo de EspíritoSanto (2013). Ademais, as observações in loco na cidade fronteiriça demonstraram que o francês ocupa um lugar importante na realidade fronteiriça, já que o mesmo está presente em placas de trânsito, outdoors e sinalizações. Pereira (2009) vislumbra uma intensificação do ensino de francês língua estrangeira (FLE) em Oiapoque, já que o francês é, sem dúvida, a língua de mercado, das trocas comerciais e econômicas entre os países vizinhos.

\section{ANÁLISE DE DOCUMENTOS OFICIAIS BRASILEIROS}

Este último tópico tem o objetivo de analisar os documentos oficiais que trazem dados relativos à situação sociolinguística e questões relativas à política linguística oficial adotada, ou seja, aquela implementada via ação estatal. Assim, para percorrermos o caminho a que se pretende, procuramos fazer análise dos seguintes documentos: a Constituição Federal de 1988; a Lei de Diretrizes e Bases da Educação Nacional de 1996 (LDB), a Lei ${ }^{\circ}$ 11.161/2005 - que instituiu a obrigatoriedade do ensino de espanhol nas redes de ensino brasileira e os Parâmetros Curriculares Nacionais de Língua Estrangeira (PCNs/1998). Abordaremos também a Lei $\mathrm{n}^{\mathrm{0}} 13.415$ promulgada em 17 de fevereiro de 2017, que trouxe profundas alterações na LDB, além de revogar a Lei $n^{\circ} 11.161 / 2005$.

No Brasil, a política linguística desenvolvida ao longo do século XX foi sempre atrelada a uma visão de estado monolíngue, que por meio dessa estratégia, visava demarcar as fronteiras e constituir um ideal de unidade nacional. As políticas linguísticas homogeneizadoras não são recentes. Do descobrimento do Brasil até a Independência, a Língua Portuguesa foi considerada "Companheira do Império", 
ou seja, a única legitimada tanto pelo Brasil quanto por Portugal (OLIVEIRA, 2009). Durante o século XX, o mito do monolinguismo intensificou-se com o programa governamental de Vargas denominado "Campanha de Nacionalização", que consistia num conjunto de medidas tomadas para diminuir a influência das comunidades de imigrantes estrangeiros no Brasil e forçar sua integração junto à população brasileira.

Com o advento da Constituição Federal de 1988, o Português perde o status de única "língua nacional" e ganha o status de "língua oficial" (Art. 13). A diferença é sutil, mas pressupõe a existência de outras línguas - não oficias - em território nacional. Além disso, a Constituição reconhece e legitima as línguas indígenas em todo o território nacional. No Art. $210 \$ 2^{\circ}$ lê-se que "O ensino fundamental regular será ministrado em língua portuguesa, assegurada às comunidades indígenas também a utilização de suas línguas maternas e processos próprios de aprendizagem". Esse artigo garante, institucionalmente, os direitos linguísticos e culturais das comunidades indígenas.

Outra política linguística favoreceu uma situação de multilinguismo no Brasil, a Lei de Diretrizes e Bases (LDB/1996). A LDB, além de tratar da educação bilíngue e intercultural para os povos indígenas (artigos 78 e 79), regula o ensino de línguas estrangeiras no currículo básico. Até a promulgação da Lei $n^{0} 13.415 / 17$, estava previsto que na parte diversificada do currículo seria "incluído, obrigatoriamente, a partir da quinta série, o ensino de pelo menos uma língua estrangeira moderna, cuja escolha ficará a cargo da comunidade escolar, dentro das possibilidades da instituição" (Art. 26, parágrafo quinto. Além disso, o texto legal também garantia a inclusão de "uma língua estrangeira moderna, como disciplina obrigatória, escolhida pela comunidade escolar, e uma segunda, em caráter optativo, dentro das disponibilidades da instituição" (Art. 36, inciso III, grifo nosso). Veja que, como estava disposto no texto da lei, existia uma abertura ao ensino de outras línguas estrangeiras, não havendo, portanto, uma predileção para o ensino de um determinado idioma. Contudo, a LDB foi alterada pela lei 13.415/17 e o teor de tais artigos não vigoram mais com mesma redação, conforme veremos mais adiante.

O Brasil, amparado pelo bloco do MERCOSUL, conformou uma política linguística bilateral com países do cone Sul que abarcou a particularidade linguística complexa das regiões fronteiriças hispanófonas. Com o estreitamento das relações com os países de fronteira do eixo sul tem-se o interesse em difundir a aprendizagem dos idiomas oficiais do MERCOSUL o que resultou na promulgação da Lei $\mathrm{n}^{\mathrm{0}} 11.161 / 05$ de 2005 que determinava a obrigatoriedade de as escolas ofertarem o ensino de espanhol para o ensino médio: "O ensino da língua espanhola, de oferta 
obrigatória pela escola e de matrícula facultativa para o aluno, será implantado, gradativamente, nos currículos plenos do ensino médio". (Art. $1^{\circ}$ ). Ressalta-se aqui que, a Lei $n^{\circ}$ 11.161/05 impunha a oferta obrigatória do espanhol no Ensino Médio, restringindo substancialmente a diversidade linguística tanto visada no âmbito da LDB. Em que pese essa crítica, a lei teve o mérito de garantir a oferta do ensino de espanhol, favorecendo, sobretudo, as regiões de fronteira com países de língua oficial espanhola. Contudo, com a promulgação da lei n ${ }^{0}$ 13.415/17 houve uma revogação expressa da Lei ${ }^{\circ} 11.161 / 05$ e a oferta do espanhol não é mais obrigatória em todo território nacional.

A oferta do espanhol é também abordada pelos Parâmetros Curriculares Nacionais de Língua Estrangeira (PCNs) do $3^{\circ}$ e $4^{\circ}$ ciclo do Ensino Fundamental. Tais parâmetros visam difundir os princípios da reforma curricular e orientar os professores na busca de novas abordagens e metodologias. Observe o fragmento abaixo retirado dos PCN's de Língua Estrangeira:

No Brasil, tomando-se como exceção o caso do espanhol, principalmente nos contextos das fronteiras nacionais, e o de algumas línguas nos espaços das comunidades de imigrantes (polonês, alemão, italiano etc.) e de grupos nativos, somente uma pequena parcela da população tem a oportunidade de usar línguas estrangeiras como instrumento de comunicação oral, dentro ou fora do país (PCN do $3^{\circ}$ e $4^{\circ}$ ciclo do E.F., 1998, p.20).

A análise do trecho acima nos permite fazer as seguintes constatações: (1) As fronteiras hispanófonas são consideradas como "fronteiras nacionais", excluindo por completo as fronteiras não-hispanófonas, como o caso da Fronteira BrasilGuiana Francesa; (2) As línguas de fronteira (espanhol), as línguas autóctones (línguas indígenas) e as alóctones (línguas de imigração) são casos de exceção à política linguística brasileira (está explícita uma política linguistica monolingue), (3) a situação plurilíngue no Brasil é pouco problematizada já que "somente uma pequena parcela da população tem a oportunidade de usar línguas estrangeiras".

Mais adiante, nos PCNs de língua estrangeira do $3^{\circ}$ e $4^{\circ}$ ciclo do Ensino Fundamental é discutida a inclusão de línguas em comunidades alóctones e autóctones. De acordo com os PCNs, a inclusão de determinadas línguas justificase não somente pela necessidade de resguardar a identidade local, mas também com forma de preservar a história, os fatos relativos às comunidades locais e os fatores relativos à tradição:

A convivência entre comunidades locais e imigrantes ou indígenas pode ser um critério para a inclusão de determinada língua no currículo escolar. Justifica-se pelas relações envolvidas nessa convivência: as relações culturais, afetivas e de parentesco. Por outro lado, em comunidades indígenas e em comunidades de surdos, nas quais a língua materna não é o português, justifica- 
se o ensino de Língua Portuguesa como segunda língua. (PCN do $3^{\circ}$ e $4^{\circ}$ ciclo do E. F.,1998, p.23)

Ao confrontarmos as passagens acima retiradas dos PCNs do $3^{\circ}$ e $4^{\circ}$ ciclo do Ensino Fundamental fica evidente diferentes visões veiculadas no mesmo documento sobre as minorias linguísticas. Enquanto na primeira passagem, os contextos de fronteira e as comunidades de imigrantes e indígenas estão colocados à margem e tidos como uma exceção à regra de uma política linguistica brasileira préestabelecida, na segunda passagem, as questões relacionadas às minorias linguísticas estão no cerne da política linguística.

\subsection{A Lei $n^{\circ} 13.415$ de 17 de fevereiro de 2017 e a ameaça à abertura linguistica}

A promulgação da Lei $n^{\circ} 13.415 / 17$ trouxe profundas mudanças na política linguistica para línguas estrangeiras em território nacional. Primeiramente promulgada em forma de medida provisória, desconsiderando a opinião de especialistas, professores e sociedade civil, as mudanças foram posteriormente convertidas em lei em 17 de fevereiro de 2017. A mudança mais significativa é a predileção feita pela língua inglesa nos currículos da educação básica. Assim, se antes, estava previsto que a partir da quinta série era obrigatório o ensino de pelo menos uma língua estrangeira moderna, com a nova lei passa a ser obrigatório o ensino do inglês a partir do sexto ano do ensino fundamental. A nova lei também incluiu o artigo 35-A na LDB ao tratar do currículo do ensino médio, fazendo constar a seguinte redação no parágrafo quarto:

$\S 4$-Os currículos do ensino médio incluirão, obrigatoriamente, o estudo da língua inglesa e poderão ofertar outras línguas estrangeiras, em caráter optativo, preferencialmente o espanhol, de acordo com a disponibilidade de oferta, locais e horários definidos pelos sistemas de ensino (Lei $\left.{ }^{\circ} 13.415 / 17\right)$.

Pelo que se percebe o ensino da língua inglesa ganha um status privilegiado no sistema educacional brasileiro, sendo que a oferta de outras línguas estrangeiras, inclusive o espanhol, será apenas em caráter optativo. A nova lei representa um retrocesso no caminho de abertura à diversidade linguistica experimentada até então, desde a promulgação da Constituição de 88 . Nesse sentido, o que pode ser alegado é que a nova lei ao invés de reforçar o multilinguísmo e respeitar a diversidade linguistica em todo território nacional, sobretudo nas áreas fronteiriças, reduz a possibilidade do sistema educacional brasileiro em se adaptar as diferentes realidades sociolingüísticas locais. Aceitar que somente o ensino de língua inglesa 
seja obrigatoriedade num país com população pluriétnica, com $23.102 \mathrm{~km}$ de fronteira, com 10 países fronteiriços, com mais de 30 cidades-gêmeas formalmente reconhecidas e que recebe anualmente mais de 6 milhões de turistas, é desconsiderar toda a diversidade cultural presente no território nacional. Ademais, o contexto global de intensas trocas culturais e econômicas, bem como os fluxos migratórios constantes exigem dos países uma política linguistica moderna e alinhada com os modernos princípios de respeito à diversidade linguistica e cultural dos povos.

A conclusão a que se chega é que os documentos oficiais não estão em consonância e possuem diferentes objetivos e metas, comparando-se uns com os outros. Até a promulgação da Lei ${ }^{\circ}$ 13.415/17 o aparato legislativo brasileiro caminhava para uma abertura à diversidade linguística. A Constituição Federal de 1988 representa o principal marco dessa abertura ao retirar do português o estatuto de língua nacional e reconhecer a existência de outras línguas no território nacional. A LDB, antes de sua alteração em 2017, avançou nesse processo ao tornar obrigatório o ensino de outras línguas estrangeiras modernas na Educação Básica, além de um respaldo a línguas e culturas indígenas. A Lei $\mathrm{n}^{\mathrm{O}}$ 11.161/05 voltou-se para a obrigatoriedade da oferta do ensino de espanhol no Ensino Médio favorecendo, sobretudo, as populações residentes em regiões fronteiriças com países de língua oficial espanhola. Os PCN's analisados ora inserem as línguas minoritárias (línguas de imigração, línguas de fronteira e línguas indígenas) na pauta das discussões, ora as colocam em casos de exceção. Por fim, identificamos que a Lei $n^{\circ}$ 13.415/17 é promulgada na contramão dos preceitos da legislação brasileira vigente, das modernas legislações mundiais sobre o tema de ensino de línguas estrangeiras, bem como de toda discussão acadêmica sobre a pluralidade linguistica.

Assim, pelo que fora exposto nesta seção, urge mais do que nunca discutir a política linguistica para línguas estrangeiras no Brasil, sob o risco de perdemos todo avanço conquistado até aqui. É preciso que mais trabalhos sejam divulgados para fomentar as discussões sobre a política linguistica brasileira a fim de contribuir para o debate acadêmico e quem sabe, sensibilizar políticos a demais atores governamentais para a necessidade de uma conformação de uma política linguistica que realmente expresse nossa diversidade cultural e que esteja alinhada com os modernos princípios de respeito a diversidade linguistica dos povos.

\section{CONCLUSÃO}

No curso deste presente trabalho procuramos apresentar o percurso epistemológico da área de política linguística ressaltando sua evolução ao longo de 
cinco décadas. Em seguida, buscamos descrever brevemente o histórico das relações bilaterais Brasil-Guiana Francesa, revelando ações conjuntas entre os respectivos países. Fizemos uma análise (não-exaustiva) de estudos representativos na área da sociolinguística sobre a fronteira franco-brasileira e buscamos compreender documentos oficiais brasileiros que trazem dados relativos à política linguística adotada nessa área fronteiriça. Nosso principal objetivo foi o de apresentar um panorama da realidade linguistica fronteiriça Brasil-Guiana Francesa e refletir sobre a política linguística brasileira presente nos documentos oficiais analisados.

Os estudos analisados no âmbito da sociolinguística mostraram que a língua francesa ocupa lugar de destaque na fronteira Brasil-Guiana Francesa. Fruto de representações positivas "língua bonita", "língua útill", considerado língua das "trocas econômicas", "língua comercial" e presente em placas e sinalizações de Oiapoque, o francês tem se mostrado uma língua com potencial crescimento na região fronteiriça. Apesar disso, as políticas linguísticas adotadas pelo Estado brasileiro pouco têm beneficiado a comunidade fronteiriça. O estudo pioneiro de Nascimento (2005) revelou que na fronteira Brasil-Guiana se tem uma predileção do ensino do inglês e do espanhol em relação ao francês - refletindo uma realidade nacional e não local. De acordo com a pesquisadora, a concepção de "país monolíngue" - ainda presente na França e no Brasil - advém de uma visão nacionalista exarcebada, e tal concepção não favorece a implementação de políticas linguísticas multilíngues, que levem em conta áreas fronteiriças, línguas minoritárias e contextos particulares.

Espírito-Santo (2013), por sua vez, evidenciou que a implementação do francês no ensino público em Oiapoque emana de iniciativa civil - realizada por agentes locais - e sem respaldo das leis vigentes em território brasileiro. Ademais, esse estudo mostrou que as fronteiras sul, amplamente amparadas pelo advento do MERCOSUL, entram para pautas de discussões e têm suas necessidades levadas em consideração, ao passo que as fronteiras ao norte, como, por exemplo, as cidades gêmeas Oiapoque/Saint George - são "esquecidas" pelo poder público e são desprovidas de ações que as beneficiam. Observamos, a partir da analise do último estudo, o de Pereira (2009), que os entrevistados, além de terem uma representação positiva da língua francesa, padecem do ensino desse idioma que favoreceriam as relações cotidianas e profissionais. Para a pesquisadora, o ensino de francês língua estrangeira (FLE) é promissor no futuro da comunidade fronteiriça.

Pela análise de documentos oficiais observamos que, com certa frequência, os documentos oficiais se contradizem e que possuem ambiguidades, inclusive no interior de um mesmo documento. A Constituição Federal (1998) institui o português como língua oficial e leva em consideração as necessidades das 
comunidades indígenas. Por outro lado, a LDB (1996) que até 2017 previa a oferta de pelo menos uma língua estrangeira nos anos finais do Ensino Fundamental, passa a privilegiar o ensino do inglês em detrimento de outras línguas. A Lei n ${ }^{\circ}$ 11.161/05 que garantiu a obrigatoriedade do espanhol no Ensino Médio foi revogada quando da promulgação da Lei $n^{\circ}$ 13.415/17. Esta última lei significa um retrocesso no que diz respeito à abertura à diversidade linguistica no Brasil, ameaçando as conquistas já alcançadas. Os documentos evidenciaram também que as políticas linguísticas oficiais adotadas pelo Estado brasileiro raramente citam as línguas minoritárias (línguas indígenas, línguas de fronteira, línguas de imigração). A análise dos PCNs apontou que ainda há uma visão monolíngue da língua em nosso território, atrelada a uma concepção nacionalista "... somente uma pequena parcela da população tem a oportunidade de usar línguas estrangeiras..." (PCN do $3^{\circ}$ e $4^{\circ}$ ciclo do Ensino Fundamental,1998, p.20). Os PCNs concebem as fronteiras sul como "fronteiras nacionais" e desconsideram completamente outros contextos fronteiriços, como por exemplo, a fronteira do Brasil-Guiana Francesa.

A partir da análise dos estudos sociolinguísticos e dos documentos oficiais brasileiros constatamos que a região fronteiriça Brasil-Guiana Francesa carece de políticas linguísticas que levem em consideração as necessidades prementes da população. A título de esboço, pensamos que a adoção de políticas linguísticas multilíngues, como por exemplo, o Programa Escolas Interculturais de Fronteira (PEIF) poderiam ser implementadas nas fronteiras norte do Brasil. O Programa Escolas Interculturais de Fronteira (PEIF) é desenvolvido no âmbito do MERCOSUL, em cidades brasileiras da faixa de fronteira de um lado e em suas respectivas cidades-gêmeas de países que fazem fronteira com o Brasil, de outro. Atualmente, o principal objetivo do programa é promover a integração regional por meio da educação intercultural que garanta formação integral às crianças e aos jovens nas regiões de fronteira do Brasil com outros países. Contudo, tal experiência ainda não foi ampliada para outras faixas de fronteira do país, como por exemplo, o Suriname, a Guiana e a Guiana Francesa.

Por fim, sublinhamos que não foi nosso propósito esgotar o tema. O presente artigo teve a intenção de resenhar algumas questões em aberto relativas à fronteira Brasil-Guiana Francesa, traçando ações bilaterais, elencando estudos consistentes e discutindo políticas linguísticas referentes ao contexto estudado. Concluímos, a partir dos estudos aqui analisados que: 1. O francês é uma língua com potencial crescimento na fronteira Brasil-Guiana uma vez que é falado nas relações cotidianas; 2. A área fronteiriça carece de políticas linguísticas oficiais que promovam o ensino do francês na fronteira, já que as políticas existentes são iniciativas civis. 3. A 
legislação brasileira está voltada para a realidade nacional e as realidades locais não estão previstas em forma de lei (como o caso da fronteira Brasil-Guiana Francesa) ou são previstas como exceção (as demais fronteiras, as línguas de imigração e as indígenas). Espera-se com esse trabalho chamar a atenção dos pesquisadores sobre a necessidade de se pensar nas políticas linguísticas da fronteira norte do país para que o tema ganhe a agenda política.

\section{REFERÊNCIAS BIBLIOGRÁFICAS}

BRASIL. Constituição (1988). Constituição da República Federativa do Brasil de 1988. Disponível em: http://www.planalto.gov.br/ccivil_03/constituicao/ constituicaocompilado.htm.Acesso em: 31 jul. 2017.

BRASIL. (1996). Lei n. ${ }^{\circ}$ 9394, de 20 de dezembro de 1996. Estabelece as diretrizes e bases da educação nacional. Disponível em: http://www.planalto.gov.br/ccivil_03/leis/ L9394.htm. Acesso em: 31 jul.2017.

BRASIL. (1998). Ministério da Educação. Secretaria de Educação Fundamental. Parâmetros Curriculares Nacionais para o terceiro e quarto ciclos $\left(5^{\mathrm{a}}\right.$ a $8^{\mathrm{a}}$ série $)$ do ensino fundamental: língua estrangeira. Brasília: MEC/SEF.

BRASIL. (2005). Lei n. ${ }^{0} 11.161$, de 5 de agosto de 2005. Dispõe sobre o ensino da Língua Espanhola. Disponível em: http://www.planalto.gov.br/ccivil_03/_Ato20042006/2005/Lei/L11161.htm. Acesso em: 25 mai. 2016.

BRASIL. Ministério da Educação. Escolas de fronteira. Programa Escolas Bilíngues de Fronteira (PEBF). Disponível em: http://portal.mec.gov.br/escola-de-fronteira/ escola-de-fronteira. Acesso em: 25 mai. 2016.

BRASIL. Ministério da Educação. Programa intercultural terá mais países, cidades e idiomas. Disponível em: http://portal.mec.gov.br/ultimas-noticias/211-218175739/19218programa-intercultural-tera-mais-paises-cidades-e-idiomas. Acesso em: 25 mai. 2016.

BRASIL. Ministério da Educação. Escolas de fronteira. Disponível em: http:// educacaointegral.mec.gov.br/escolas-de-fronteira. Acesso em: 25 mai 2016.

BRASIL. Ministério das Relações Exteriores. República francesa: Cronologia das relações bilaterais. Disponível em: http://www.itamaraty.gov.br/pt-BR/ficha-pais/5176republica-francesa. Acesso em: 03 jun.2016. 
BRASIL. Lei $\mathrm{n}^{\mathrm{O}}$ 13.415, de 16 de fevereiro de 2017. Disponível em: http://www.planalto. gov.br/ccivil_03/_ato2015-2018/2017/lei/L13415.htm. Acesso em 31 jul.2017.

CALVET, L.-J. (1996). Les politiques linguistiques: Que sais-je ?.Paris: Presses Universitaires de France Ed.

ESPIRITO-SANTO, M.M. (2009). "De Oiapoque a Saint-George": uma pesquisa sociolingüística em meio escolar na fronteira Brasil e Guiana Francesa. 108 f. Dissertação de Mestrado em Letras. Departamento de Letras do Centro de Teologia e Ciências Humanas, Pontifícia Universidade Católica do Rio de Janeiro, Rio de Janeiro.

GRENIER, G.-M. (2011). Guiana Francesa-Amapá: melhor estruturar os territórios para intensificar os intercâmbios. Disponível em: https://www.epsilon.insee.fr/jspui/ bitstream/1/15698/1/cerom_gy_Amapa_portugais.pdf Acesso em: 29 mar.2017.

NASCIMENTO, K.C.M. (2005). A Situacao Sociolinguistica da Fronteira Franco-Brasileira: Oiapoque \& Saint Georges. 106 f. Dissertação de Mestrado em Letras. Departamento de Letras do Centro de Teologia e Ciências Humanas, Pontifícia Universidade Católica do Rio de Janeiro, Rio de Janeiro.

NASCIMENTO, K.C.M. (2013). Fronteiras linguísticas e fronteiras políticas: Relações linguísticas e sociohistóricas na Fronteira do Brasil com a Guiana Francesa. In: Cadernos de Letras da UFF. v. 23, n ${ }^{\circ} 47$, pp.163-182.

OLIVEIRA, G. M. (2009). Brasileiro fala português: Monolinguismo e Preconceito Linguístico. Revista Linguasagem, $11^{\text {a }}$ Edição, pp.1-9.

PEREIRA, T. (2009). Representação e aprendizagem de uma língua estrangeira: status da língua francesa em contexto urbano e de fronteira. Synergies Brésil n 7, pp. 101-111.

RICENTO, T. (Ed.). (2000). Historical and Theoretical Perspectives in Language Policy and Planning. In: (Org.). Ideology, politics, and language policies: Focus on English. Amsterdam/Philadelphia: John Benjamins. p. 9-24.

RUCKERT, A. A.; SILVA, G.V. (2009). A fronteira Brasil-França: mudança de usos político-territoriais na fronteira entre Amapá (BR) e Guiana Francesa (FR). Confins. $\mathrm{n}^{\circ}$ 7. Disponível em: https://confins.revues.org/6040?lang=pt. Acesso em: 28 mar. 2017.

SCHIFFMAN, H. F. (1996). Linguistic culture and Language Policy. London: Routledge.

SHOHAMY, E. (2006). Language policy: bidden agendas and new approaches. London: Routledge. 
A política linguística na região fronteiriça Brasil-Guiana Francesa...

SPOLSKY, B. (2004). Language policy. New York: Cambridge University Press.

STURZA, E.R. (2006.) Línguas de fronteira e Políticas de línguas: Uma História das Idéias Linguísticas. Tese de Doutorado em Linguística. Instituto de Estudos da Linguagem, Unicamp, Campinas.

Recebido: 01/04/2017

Aceito: 02/08/2017 